\title{
Sexual dysfunction in diabetic patients - an important and overlooked complication
}

\section{ABSTRACT}

Introduction. Diabetes affects over 415 million of the world population. In Poland, the number of diabetics reaches 3 million people with more than one million of patients unaware about their disease. A large number of people with diabetes struggle with numerous complications including area of sexual dysfunction, resulting from improperly controlled blood glucose.

Material and methods. The study used a proprietary three-part questionnaire for the evaluation of sexual satisfaction in patients with diabetes. Participation in the study included 110 patients with diabetes. The average age of the respondents was 42.2 (SD = 15.82). Results. The loss or decrease of interest in sex life were the most frequently reported by patients with diabetes problems in the field of sex life. More than $40 \%$ of patients are dissatisfied with their sex lives. Half of the patients have the sex life contrary to their expectations. The respondents using insulin injections had significantly lower level of sexual satisfaction than patients using insulin pumps.

Conclusions. Satisfaction with sex life is a key component of the patient's wellbeing. People with diabetes rarely evaluate their lives as satisfactory. The results of the study open the working area for professionals, which will result in improving the quality of sex life of patients with diabetes. We hope that the results of our research will contribute to improving patients quality of life by encouraging physicians to pay closer

Address for correspondence: lek. Agnieszka Maksymiuk-Kłos

Klinika Chorób Wewnętrznych, Diabetologii i Endokrynologii WUM

ul. Kondratowicza 8, 03-242 Warszawa

e-mail: agamaksymiuk@gmail.com

Clinical Diabetology 2017, 6, 4, 119-125

DOI: $10.5603 /$ DK.2017.0020

Received: 28.07.2017

Accepted: 16.08.2017 attention to the realm of sex as important source of patient satisfaction. (Clin Diabetol 2017; 6, 4: 119-125)

Key words: sexual disorders, diabetes, diabetes complications

\section{Introduction}

Diabetes as defined by the American Diabetes Association (ADA) and the Polish Diabetes Association (PTD) is a group of metabolic diseases characterized by hyperglycemia resulting from a defect in insulin secretion and/or action. Chronic persistent elevated blood glucose leads to damage, dysfunction and failure of many organs [1-3].

According to data published in the latest seventh edition of the Atlas of the IDF (International Diabetes Federation) diabetes affects globally more than 415 million people - i.e. approx. $8.8 \%$ of the world population. In addition, 318 million people have impaired glucose tolerance (IGT), a condition involving a high risk of developing diabetes. It is predicted that by 2040 the number of people with diabetes will increase to 642 million (10.4\%). The United Nations has recognized diabetes as the only noninfectious disease with epidemic status [4]. WHO lists diabetes along with hypertension and smoking cigarettes, among the most important risk factors for premature mortality in the population [5]. Currently, every $11^{\text {th }}$ person in the world has diabetes. In developed countries, $91 \%$ of all cases of diabetes are type 2 diabetes. In Poland, the number of people with diabetes is estimated at the level of more than 3 million, 1 million of which are unaware of the disease. Our country is one of the leading places in Europe in terms of prevalence $(9.03 \%)$. The systematic increase in the incidence of diabetes, both in Poland and in the world is caused by socio-cultural changes [6]. 
The dietary changes are accompanied by a drastic reduction of interest in physical activity [7]. This leads to increasingly widespread prevalence of obesity in society [8]. Both diabetes and obesity are independent risk factors for diseases of the cardiovascular system. Patients with diabetes, with poorly controlled blood glucose have a high risk of developing micro and macrovascular complications, which is further intensified by the accompanying obesity $[9,10]$. In addition, diabetic patients often have complications from the kidneys, nervous system or eyesight. Correct glycemic control is the best prevention against both early and late diabetic complications.

Complications due to poor glycemic control affect many organs and systems, and can have both acute and chronic character. Diabetic complications may also directly or indirectly affect the quality of sex life of patients [11]. Research shows the wide distribution of a variety of sexual dysfunctions in patients with diabetes are more frequent than in the healthy population [12]. Doctors are aware of existence of this complication and importance for the patient. Problems in the sex life of patients with diabetes have a multifactorial pathogenesis. Organic changes directly caused by the disease are of great importance [13]. Another group includes the psychological factors that may directly result from diabetes or be closely related to the disease $[14,15]$.

Problems concerning sex life in men often have a biological background, while women are dominated by psychogenic etiology $[13,16]$.

Difficulties in sex life can be caused by changes in the vascular, nervous, endocrine and metabolic systems [17-19]. Patients may exhibit sexual dysfunction resulting from concomitant diseases, which are a consequence of diabetes. The deterioration in the quality of sex life is significantly affected by depression [14, $20,21]$. The context of sexual problems also includes the impact of stress [22], obesity, negative assessment of body image, self-esteem drop [14, 23, 24], reduced quality of the partner relationship, problems with finding sexual partners and social isolation, and the fear of pregnancy, resulting from fear of possible diabetic complications in the mother or the child $[12,14]$. The aim of this study was to evaluate of sexual satisfaction in our patients with diabetes.

\section{Material and methods \\ Research tools}

Proprietary tools in the form of three-part questionnaire were used in the study. The first part included questions about demographic data: gender, age, education, the date of diagnosis of diabetes and the number of sexual partners.
The second part contained a description of the six situations, depicting the possible change in sexual behavior. They ranged from the cessation of sex life, the lack of change to a more active sex life. They also included such situations when a patient took substitute behavior, e.g. masturbatory behavior, withdrawing from sexual activity with another person ("My present life differs from that before receiving the diagnosis. Currently, I gave up most forms of sexual activity. Since receiving the diagnosis I have undertook sexual activity sporadically or/and it is brought to masturbation"). Patients could also choose a situation where sexual behavior has been replaced by the experience of closeness ("My present life differs from that before receiving the diagnosis. Now, more than sexual activity, I'm interested in experiencing intimacy with the partner. I prefer to e.g.: spend time with my partner, cuddle, talk"). The command includes the request to select the description that describes the patient's situation in the most accurate way.

The last part concerned the assessment of sexual satisfaction. It was made with the use of tools based on a questionnaire exploring the quality of life. The questions were adapted to the level of sexual satisfaction, which was evaluated using a seven grade scale, according to which the respondents were to determine the extent they agree with given statements (from strong disagreement to strong agreement).

The advantage of the tool lies in the application of positive, not negative definitions. In this way, multiple forms of denial were avoided, and the investigated person by reading the questionnaire could confirm the positive statement or disagree with it.

Statistical analysis was performed using Statistica 10 (Statsoft) and presented as mean \pm (SD), numbers or ratio as needed. Student's $t$-test was used to evaluate continuous variables showing normal distribution and test of rank ordering of Kruskal-Wallis for non-parametric distribution. P-values $<0.05$ were considered significant.

The implementation and the course of the study

The study was conducted in the Department of Internal Diseases, Diabetology and Endocrinology, Medical University of Warsaw and in the Central Clinical Hospital of the Ministry of Internal Affairs in Warsaw. Patients who chose to participate in the study were to fill in the questionnaire on their own, seal the envelope and leave it at the nurses' room.

\section{Participants}

The study involved 110 patients with diabetes divided into 2 groups (patients with type 1 diabetes, with 
Table 1. Characteristic of study population

\begin{tabular}{|c|c|c|c|}
\hline Characteristic & Subgroup & $\mathrm{N}$ & $\%$ \\
\hline Age & All & 42.2 & - \\
\hline \multirow[t]{2}{*}{ Gender } & Men & 60 & $54.5 \%$ \\
\hline & Female & 50 & $45.5 \%$ \\
\hline \multirow[t]{9}{*}{ Place of residence } & Country & 16 & $14.4 \%$ \\
\hline & City below & 14 & $12.6 \%$ \\
\hline & 10000 inhabitants & & \\
\hline & City $10-50000$ & 10 & $9 \%$ \\
\hline & inhabitants & & \\
\hline & City 50-100 000 & 12 & $10.7 \%$ \\
\hline & inhabitants & & \\
\hline & City more than & 58 & $53.3 \%$ \\
\hline & 100000 Inhabitants & & \\
\hline \multirow[t]{5}{*}{ Education } & Primary & 6 & $6 \%$ \\
\hline & Vocational & 30 & $27.5 \%$ \\
\hline & High school & 34 & $31 \%$ \\
\hline & College & 8 & $8 \%$ \\
\hline & Studies & 30 & $27.5 \%$ \\
\hline \multirow[t]{4}{*}{ Financial situation } & Poor & 8 & $7.5 \%$ \\
\hline & Average & 54 & $50 \%$ \\
\hline & Good & 44 & $40.7 \%$ \\
\hline & Very good & 2 & $1.8 \%$ \\
\hline \multirow[t]{2}{*}{ Stable relationship } & No & 80 & $72.7 \%$ \\
\hline & Yes & 28 & $27.3 \%$ \\
\hline
\end{tabular}

Table 2. The most common diseases in study population

\begin{tabular}{lc}
\hline & $\%$ \\
\hline Autoimmune thyroid disease & 21.8 \\
Coronary heart disease & 11 \\
Artherosclerosis & 11 \\
Depression & 11 \\
Hypertension & 7.2 \\
Neuropathy & 7.2 \\
Urinary tract infection & 5.4 \\
Periarticular ossification & 5.4 \\
Asthma & 3.6 \\
\hline
\end{tabular}

type 2 diabetes). Characteristic of study population is presented in Table 1.

The study was conducted in 2014-2015. The average time that elapsed from the time of diagnosis of the disease until the study was 10-11 years.

\section{Results}

The most common disease accompanying diabetes are were presented in Table 2.
Table 3. The list of sexual problems of patients

\begin{tabular}{lcc}
\hline & Yes & $\%$ \\
\hline Erection problems & 2 & $4 \%$ \\
Premature ejaculation & 5 & $9 \%$ \\
Pain during intercourse & 2 & $4 \%$ \\
Loss or decline in sexual interest & 16 & $29 \%$ \\
Fear of failure & 3 & $5 \%$ \\
Problems with lubrication & 8 & $15 \%$ \\
Lack of pleasure & 6 & $11 \%$
\end{tabular}

Table 4. A change in the sexual activity of respondents

\begin{tabular}{lcc}
\hline & N & $\%$ \\
\hline Closeness/inactivity & 16 & $30 \%$ \\
Occasional sex/masturbation & 6 & $12 \%$ \\
No change & 24 & $45 \%$ \\
New/more frequent activities & 7 & $13 \%$ \\
\hline
\end{tabular}

The patients with diabetes identified specific issues related to their sex life. They are summarized in Table 3. The evaluation of sexual satisfaction of patients is ambiguous. Approximately $40-54 \%$ of the respondents indicated dissatisfaction with their sex lives, while 22-44\% made a positive evaluation (Fig. 1).

The study analyzed the relationship between the method of treatment of diabetes and the satisfaction with sex life (illustrated in Fig. 2). The distribution of the numbers in subgroups is disproportionate for the method of treatment. The most numerous group included patients receiving insulin injections $(n=58$; $54.7 \%)$, less numerous group included users of an insulin pump ( $n=20 ; 18.9 \%$ ); however, groups using monotherapy ( $\mathrm{n}=16 ; 15.1 \%$ ) and oral therapy in combination with insulin $(n=12 ; 11.3 \%)$ were too small to be included in the comparison. There was no difference in the symptoms reported by patients with type 1 and 2 diabetes, but difference depending on the type of treatment was noted. People with diabetes treated with insulin therapy in the form of injections had significantly lower levels of sexual satisfaction than people who used an insulin pumps. The variable concerning changes of undertaken sexual behavior was also analyzed. Due to the size of the group, the variable was modified to achieve greater numbers of categories.

Table 4 collects data on the combined categories uses the following abbreviations: the categories of "closeness/inactivity" , "new/more frequent activities", "no change" and "occasional sex/masturbation".

Most of the respondents were in a permanent relationship (72.7\%). In the entire group, the average number of sexual partners was $M=3.5(S D=5)$. Table 5 


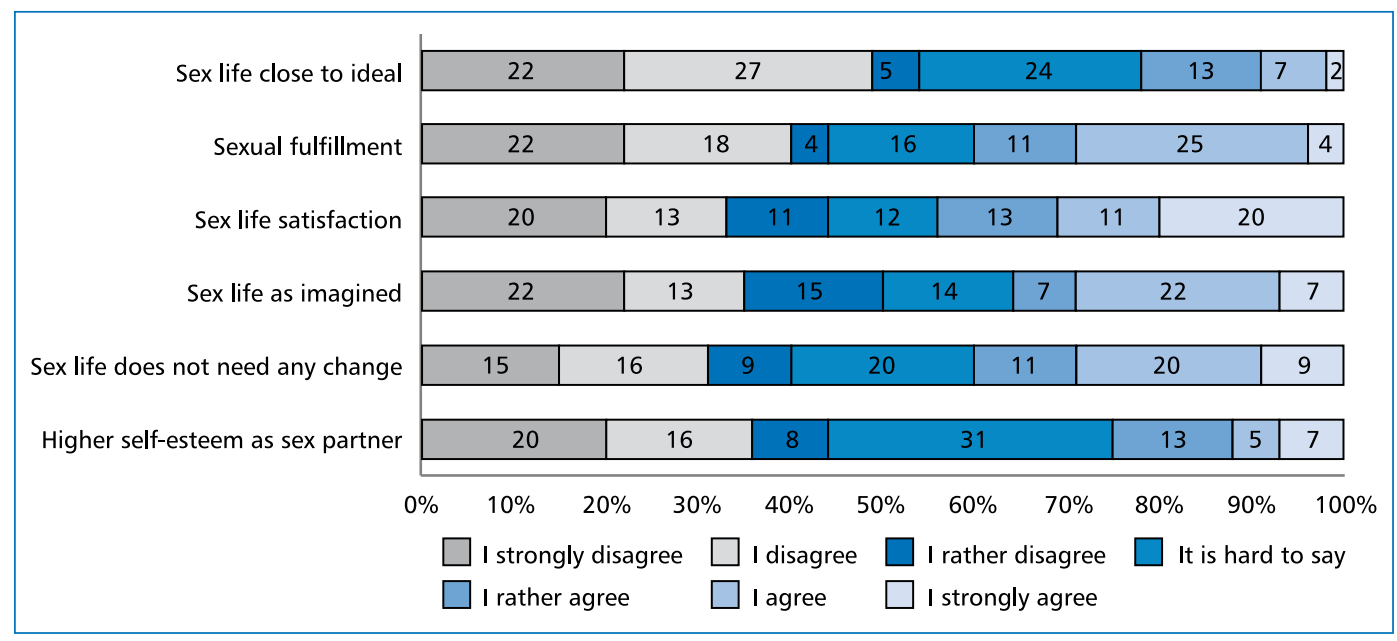

Figure 1. Distribution of the responses to questions about sexual satisfaction

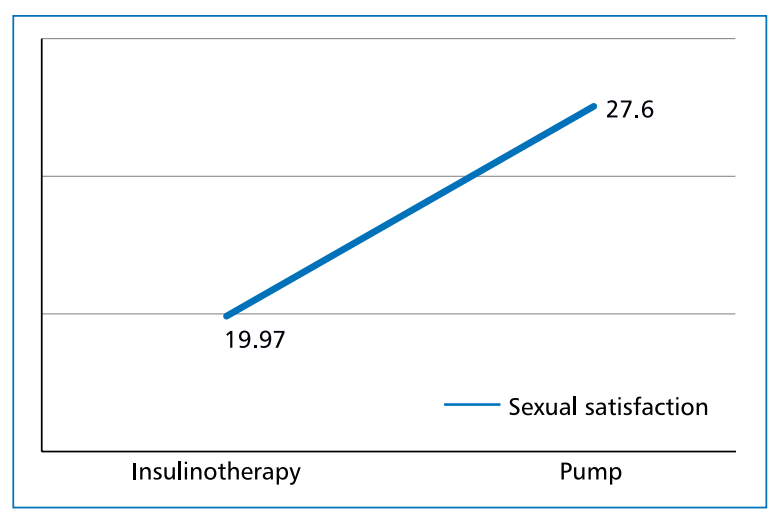

Figure 2. Sexual satisfaction versus methods of treatment of diabetes

summarizes the average number of sexual partners, depending on the type of diabetes.

$45 \%$ of respondents declared that their current sex life is no different from that before receiving a diagnosis of diabetes. Fewer patients said that at present they are not sexually active and instead of such activity they prefer the feeling of emotional closeness with the partner or they limit the activity to masturbatory behavior $(42 \%)$. Only $13 \%$ believe that since receiving the diagnosis of diabetes the have been more sexually active.

Analysis of differences for sexual satisfaction factor showed that the differences between the groups were statistically significant. Figure 3 shows how patients rated their sexual satisfaction depending on how their sexual activity changed since the time of diagnosis of diabetes.

Starting new sexual activities by patients and no changes in sexual behavior (correlate with an increase

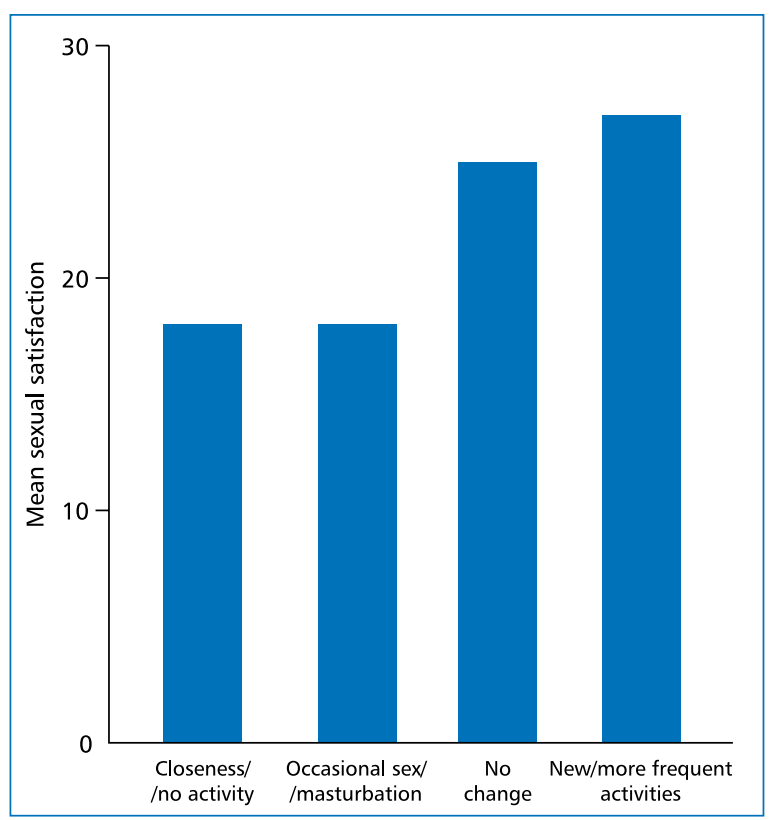

Figure 3. Sexual satisfaction versus a change in sexual behavior

Table 5. The average number of sexual partners, depending on the diagnosis

\begin{tabular}{cccccccc}
\hline & N & M & Me & Min & Max & Md & SD \\
\hline Type 2 & 56 & 3.79 & 2 & 0 & 30 & 1 & 5.88 \\
Type 1 & 48 & 2.92 & 2 & 0 & 10 & 1 & 2.38 \\
\hline
\end{tabular}

in satisfaction with sex life. At the same time, the assessment of sexual satisfaction is lower when the patients are not sexually active, or bring their sex life substitute behavior. 


\section{Discussion}

The patients used the positive phrases to describe sex life in $22-44 \%$ of cases. These results are difficult to relate to other research because the publications are characterized by significant methodological divergence. The incidence of sexual dysfunction in women with diabetes is estimated to amount $14-85 \%[14,25$, 26]. According to Jackson's research [27], persistent erectile dysfunction was observed in $34 \%$ of patients and in $24 \%$ they appeared from time to time. In the study of Lindau [28] a similar result was obtained erection problems were reported in $36 \%$ of patients. In addition, $29 \%$ of those who achieved an erection in an undisturbed way were unable to experience orgasm. It is believed that this was the effect of psychosocial factors specific to diabetic patients. The authors of this publication also indicated that similar problems also refer to men with undiagnosed diabetes (32\%).

More than half of patients (50\%) marked that is sex life is not close to ideal.

Proper conduct of sexual functions is conditioned by the efficient operation of multiple systems, organs and chemicals [29]. The decrease in the level of satisfaction with sex life may be affected by various factors. More than half of the patients included in the study had been diagnosed with type 2 diabetes. This can have a significant impact on the emergence of a broad spectrum of disorders of sex life $[25,26,28]$. The combination of mature age of a patient with the diagnosis of diabetes, strongly multiplies the risk of emergence of various types of sexual problems. Two out of three men and every third woman suffering from diabetes in the age group 57-85 years take sexual activity [28]. At the same time, people in this age range often report problems with sexual function, which cause dissatisfaction in men and motivated women to avoid sex. Studies of Mezones-Holguin [30] show that women diagnosed with diabetes more often report sexual dysfunction as a result of menopause than healthy women of the same age $(75 \%$ and $30.6 \%)$.

It is impossible to clearly determine the direction of the impact of diabetes on the emergence of sexual dysfunction. The results of published studies are often contradictory. The literature contains reports indicating no difference in the incidence of sexual dysfunction between type 1 and type 2 [26, 31]. According to other research, people suffering from type 2 diabetes more often experience problems in sex life [18, 29, 32-35].

Our research did not include all the possible causes of sexual dysfunction. According to our results, the level of satisfaction with sex life in patients with diabetes may be affected by the loss or decrease of interest in sex $(29 \%)$, problems with lubrication $(15 \%)$, lack of pleasure felt during intercourse (11\%), erectile dysfunction and pain during intercourse (4\%).

The number of people who reported these disorders in the course of study is smaller than expected (referring to data in the literature). For example, erectile dysfunction, according to research of Jackson [27] and Lindau [28] applies to $24-36 \%$ of patients. Problems with lubrication occur in $14-76 \%$ of patients with diabetes, and the problem of feeling pain in 1-66\% of women [14, 26, 34]. Vaginal dryness and pain are related phenomena, and pain in a sexual context is considered on multi-dimensional level [20].

The problem of pain draws attention to the link between the difficulties of organic and psychosocial nature. The latter include, among others: the impact of stress, the role of obesity and its connection with assessment of one's body image, self-esteem and poor partnerships $[14,20,23,24]$.

The study analyzed the levels of sexual satisfaction in patients with various types of diabetes and using different forms of treatment. The level of sexual satisfaction did not depend on the type of diabetes but the type of treatment. It turns out that patients using insulin pump are more satisfied with their sex life compared to patients treated with insulin injections. This result is likely to be associated with patients' age difference. Most of the patients receiving insulin by injection are people in their late adulthood. A large group of patients using insulin pump are young people. This interpretation refers to the impact of the age of the patients on their sex life. This result can also be linked with existing in society aforementioned stereotypes that affect both the medical personnel and the patients themselves. Higher levels of sexual satisfaction in patients using an insulin pump may also result from better education of these patients and greater awareness of their illness. People using an insulin pump are more active in the process of their treatment and usually have better control of blood glucose levels, which translates to lower risk of complications of the disease.

Another explanation of the results may include mentioned in the literature changes in the perception of body image. Traces of injections have a negative effect on some patients.

A factor comprising a change in the sexual activity was introduced to the test model. Respondents were asked to assess whether there was a change in this area, where the borderline had a form of diagnosis of diabetes. After decoding the category used in the questionnaire, it turned out that $45 \%$ of patients lead a similar sex life as before. Patients declare that they undertake sexual activity in a similar form and with 
similar frequency and they do not believe that their capabilities have changed in any way.

At the same time, it turned out that $30 \%$ of patients are currently more interested in the intimacy with their partners than in sex activity or completely withdrew from sex life. Both of these situations have been considered as close to each other, because satisfying the need of closeness, intimacy, and a sense of security with the exception of sex life was treated as compensation of sexual desire. Under normal conditions, the sex life with a partner is, inter alia, to provide the above mentioned stimuli. If a person has been sexually active, but due to certain factors, his/her behavior changes, transforming itself in such a form that can be understood as a withdrawal from sex life compensated by a higher level of emotionality. This is confirmed in the literature, especially among women. Küçük et al. [12] indicate patients who deliberately withdrew from sex life because of the illness and define it as a problem. The circumstances in which patients declare that the sex life does not matter to them are very hard, because then it is extremely difficult to determine whether this approach reflects the real feelings and how much stems from the defense mechanisms [12].

$12 \%$ of patients who, instead of the current sex life, engage in sexual activity sporadically or fulfill their desire by masturbation is another group with a negative prognosis. If a person prefers masturbation rather than sexual intercourse with partner (and in the case of not having one, not trying to find such relation for the same reason), is considered a situation going beyond the limit of a standard [36].

Only $13 \%$ of patients are now more sexually active or introduced new interactive behaviors, appropriate to their abilities resulting from health.

In conclusion, $42 \%$ of patients intentionally or by the operation of the defense mechanisms are withdrawn from sexual activity, or substantially reduce the same. A similar mechanism is also noticeable in other studies. Some publications have reported that patients with diabetes are sexually active in only $60 \%$ of men and women [12]. In other studies, the observed differences are based on gender. The authors report that sexual activity is taken by $61 \%$ of men and only $33 \%$ of women [28]. Generally, a review of research carried out by Ozcan [37] shows that $40-70 \%$ of patients withdraw from sex life.

A factor presenting the change in the sexual behavior is very important for the study, because the described level of sexual satisfaction is an expression of the subjective assessment of patients, while a form of undertaken sexual activity or withdrawal from the sex life allows for an objective attempt to assess the quality of sex life of patients.

\section{Conclusions}

Satisfaction with sex life is an important aspect of the broadly defined wellbeing of the patient. Diabetic patients rarely assess their sexual life as satisfactory. This study indicates the existence of factors that correlate positively with an increase in patient's satisfaction with undertaken sexual activity. One of them is the change in sexual activity. Another factor relates to the form of diabetes treatment. Despite many studies and awareness of the problem patients with these complication do not receive support from doctors. It seems that these make room for new approach by specialists, which will result in improving the quality of sex life of patients with diabetes.

\section{REFERENCES}

1. American Diabetes Association Guidelines. http://care.diabetesjournals.org/content/36/Supplement_1/S67.full.

2. Zalecenia kliniczne dotyczące postępowania u chorych na cukrzyce 2015. Stanowisko Polskiego Towarzystwa Diabetologicznego. Diabetologia Klin. 2015; 4(suppl A).

3. Gajewski P. Interna Szczeklika. Medycyna Praktyczna, Kraków. 2015.

4. ONZ. Resolution adopted by the General Assembly. 20 December. 2006; 61: 255

5. World Health Organization, editor. Global health risks: mortality and burden of disease attributable to selected major risks. http:// //www.who.int/healthinfo/global_burden_disease/GlobalHealthRisks_report_full.pdf (2009).

6. IDF Diabetes Atlas 2015 - 7th edition. http://www. diabetesatlas. org (2015)

7. World Health Organization, Food and Agriculture Organization UN. Diet, nutrition and the prevention of chronic diseases: report of a joint WHO/FAO expert consultation. Geneva, Switzerland, 2002.

8. Raport. Cukrzyca, ukryta pandemia. Novo Nordisk 2014

9. OECD Obesity Update 2012, Dostęp 19.07.2013. http://www. oecd.org/health/49716427.pdf (2012).

10. Ninh T. Nguyen, Xuan-Mai T. Nguyen, John Lane, Ping Wang. Relationship Between Obesity and Diabetes in a US Adult Population: Findings from the National Health and Nutrition Examination Survey, 1999-2006 OBES SURG (2011). 2010; 21: 351-355.

11. Glińska J, Skupińska A, Lewandowska M, et al. Czynniki demograficzne a ogólna jakość życia chorych z cukrzycą typu 1 i 2. Problemy Pielęgniarstwa. 2012; 20(3): 279-288.

12. Küçük $L$, Kaya $H$, Küçük $M$, et al. The Relationship Between Depression and Perception of Sexuality in Patients with Type II Diabetes: In Turkey. Sexuality and Disability. 2013; 31(1): 43-52, doi: 10.1007/s11195-012-9257-5.

13. Eren I, Erdi O, Ozcankaya R. Blood glucose control in patients with type II diabetes and the correlation of psychiatric disorders. Turkish Journal of Psychiatry. 2013; 14(3): 184-191.

14. Makara-Studzińska M, Partyka I. Zaburzenia funkcji seksualnych u kobiet chorujących na cukrzycę. Seksuologia Polska. 2011; 9(1): 22-26.

15. Goldman N, Lin IF, Weinstein M, et al. Evaluating the quality of self-reports of hypertension and diabetes. Journal of Clinical Epidemiology. 2013; 56(2): 148-154.

16. Enzlin P, Mathieu C, Van Den Bruel A, et al. Prevalence and predictors of sexual dysfunction in patients with type 1 diabetes. Diabetes Care. 2003; 26(2): 409-414, doi: 10.2337/diacare.26.2.409, indexed in Pubmed: 12547871 
17. Whitehouse $C$. Sexuality in the older female with diabetes mellitus - a review of the literature. Urologic Nursing. 2009; 29(19): 11-18, indexed in Pubmed: 19331270.

18. Bhasin S, Enzlin P, Coviello A, et al. Sexual dysfunction in men and women with endocrine disorders. Lancet. 2007; 369(9561): 597-611, doi: 10.1016/S0140-6736(07)60280-3, indexed in Pubmed: 17307107

19. Enzlin P, Mathieu C, Van Den Bruel A, et al. Sexual dysfunction in women with type 1 diabetes: a controlled study. Diabetes Care. 25(4): 672-677.

20. Mizgier M, Jarząbek-Bielecka G, Jeszka J, et al. Zaburzenia seksualne u chorych na cukrzycę w okresie pokwitania. Seksuologia Polska. 2014; 12(1): 26-30.

21. Jiménez-Garcia R, Martinez-Huedo MA, Hernandez-Barrera V, et al. Sexuality among Spanish adults with diabetes: a population-based case control study. Primary Care Diabetes. 2015; 6(4): 269-276, doi: 10.1016/j.pcd.2012.02.005, indexed in Pubmed: 22445726.

22. Giugliano F, Maiorino MI, Di Palo C, et al. Adherence to Mediterranean diet and sexual function in women with type 2 diabetes. Journal of Sexual Medicine. 2010; 7(5): 1883-1890, doi: 10.1111/j.17436109.2010.01714.x, indexed in Pubmed: 20214715.

23. Rockliffe-Fidler $C$, Kiemle $G$. Sexual function in diabetic women: A psychological perspective. Sexual and Relationship Therapy. 2003; 18(2): 143-159, doi: 10.1080/1468199031000099415.

24. Rutherford $D$, Collier $A$. Sexual dysfunction in women with diabetes mellitus. Gynecological Endocrinology. 2005; 21(4): 189-192, doi: 10.1080/09513590400021110, indexed in Pubmed: 16316838.

25. Enzlin $P$, Rosen $R$, Wiegel $M$, et al. Sexual dysfunction in women with type 1 diabetes: long-term findings from the DCCT/ EDIC study cohort. Diabetes Care. 2009; 32(5): 780-785, doi: 10.2337/ /dc08-1164, indexed in Pubmed: 19407075.

26. Nowosielski K, Skrzypulec-Plinta V. Mediators of sexual functions in women with diabetes. Journal of Sexual Medicine. 2011; 8(9): 2532-2545, doi: 10.1111/j.1743-6109.2011.02336.x, indexed in Pubmed: 21676182.

27. Jackson $G$. Sexual dysfunction and diabetes. International Journal of Clinical Practice. 2004; 58(4): 358-362, doi: 10.1111/j.13685031.2004.00180.x
28. Lindau ST, Tang H, Gomero A, et al. Sexuality Among Middle-Aged and Older Adults With Diagnosed and Undiagnosed Diabetes: A national, population-based study. Diabetes Care. 2005; 33(10): 2202-2210.

29. Buvat J. Hyperprolactinemia and sexual function in men: a short review. International Journal of Impotence Research. 2003; 15(5): 373-377, doi: 10.1038/sj.ijir.3901043, indexed in Pubmed: 14562140.

30. Mezones-Holguin E, Blümel JE, Huezo $M$, et al. Impact of diabetes mellitus on the sexuality of Peruvian postmenopausal. Gynecological Endocrinology. 2008; 24(8): 470-474, doi: 10.1080/09513590802273749, indexed in Pubmed: 18850386.

31. Izdebski Z. Seksualność Polaków na początku XXI wieku. Studium badawcze. Wydawnictwo Uniwersytetu Jagiellońskiego, Kraków 2012.

32. Ho J, Rabi D. Sexual dysfunction in women with diabetes. Canadian Journal of Diabetes. 2006; 19: 5-7.

33. Olarinoye J, Olarinoye A. Determinants of sexual function among women with type 2 diabetes in a Nigerian population. Journal of Sexual Medicine. 2008; 5(4): 878-886, doi: 10.1111/j.17436109.2007.00649.x, indexed in Pubmed: 18069996.

34. Traish A, Cushman T, Hoyt R, et al. Diabetes Attenuates Female Genital Sexual Arousal Response via Disruption of Estrogen Action. Korean Journal of Urology. 2009; 50(3): 211-223, doi: 10.4111/kju.2009.50.3.211.

35. Hidalgo-Tamola J, Chitaley K. Review type 2 diabetes mellitus and erectile dysfunction. Journal of Sports Medicin. 2009; 6(4): 916-926, doi: 10.1111/j.1743-6109.2008.01116.x, indexed in Pubmed: 19067787.

36. Ogbera AO, Chinenye $S$, Akinlade $A$, et al. Frequency and correlates of sexual dysfunction in women with diabetes mellitus. Sports Medicine. 2009; 6(12): 3401-3406, doi: 10.1111/j.17436109.2009.01396.x, indexed in Pubmed: 19627467.

37. Ozcan S, Sahin N, Bilgic D, et al. Is Sexual Dysfunction Associated with Diabetes Control and Related Factors in Women with Diabetes? Sexuality and Disability. 2011; 29(3): 251-261, doi: 10.1007/s11195-011-9209-5. 